\title{
Preface
}

\section{5th International Conference on New Frontiers in Physics 2016}

The conference series "New Frontiers in Physics" aims to promote scientific exchange and development of novel ideas in science with particular emphasis on interdisciplinarity. The main topics of the conference are high energy particle and nuclear physics, heavy ion physics, quantum optics and quantum entanglement, cosmology, astrophysics, gravity, mathematical physics.

The 5th International Conference on New Frontiers in Physics (ICNFP 2016) attracted more than 200 participants. At the opening of the Conference Dr Konstantinos Zormpas, the General Director of the Academy which hosted the conference, welcomed the participants. During the conference 7 lectures, 85 plenary and 91 parallel talks, 3 mini-workshops with 24 talks, two public talks (T. Tomaras and $\mathrm{V}$. Mukhanov), altogether, 209 oral presentations and 20 posters, were given by 233 participants. A QCD session dedicated to V. Gribov's confinement scenario and G. Altarelli Memorial Session have been organized. Also, special session took place on 11th July 2016.

A science exhibition and outreach day has been organized in the Sailing Club of Chania on 8th July 2016 by Dr. Marge Bardeen and Prof. Ch. Kourkoumeli with music and a public talk on "Gravitational waves: the confirmation which came 100 years after their prediction" by Prof. Th. Tomaras in Greek in the evening. In addition, there was a Public talk in English entitled "Gravitational waves, Cosmic Primordial Radiation and the Origin of the Universe" by Vyacheslav Mukhanov, an Opera Gala (Kalliopi Petrou (soprano), Alessia Toffanin (piano)), two classical concerts by Ruben Muradyan (piano), Svetlana (Violin), Vladimir(Cello) and Mikhail Nor (Tenor), as well as excursions and a conference dinner.

We would like to thank all the conference participants as well as the members of the International Advisory Committee, the Local Organizing Committee, the Organizing Institutes and Sponsors, the Technical University of Chania, the University of Crete at Herakleion, Christina Kourkoumeli from University of Athens, the "Go-lab European Outreach project" and the Chania Sailing Club for the organization of public events and outreach, and especially the hosting Orthodox Academy of Crete for the extremely warm atmosphere of the conference. We would also like to thank Vladimir Kovalenko from Saint Petersburg State University and the staff of "European Physical Journal Web of Conferences" for the help with publishing the proceedings.

\section{Larissa Bravina, Yiota Foka and Sonia Kabana,}

\section{Editors}

(C) The Authors, published by EDP Sciences. This is an open access article distributed under the terms of the Creative Commons Attribution License 4.0 (http://creativecommons.org/licenses/by/4.0/). 


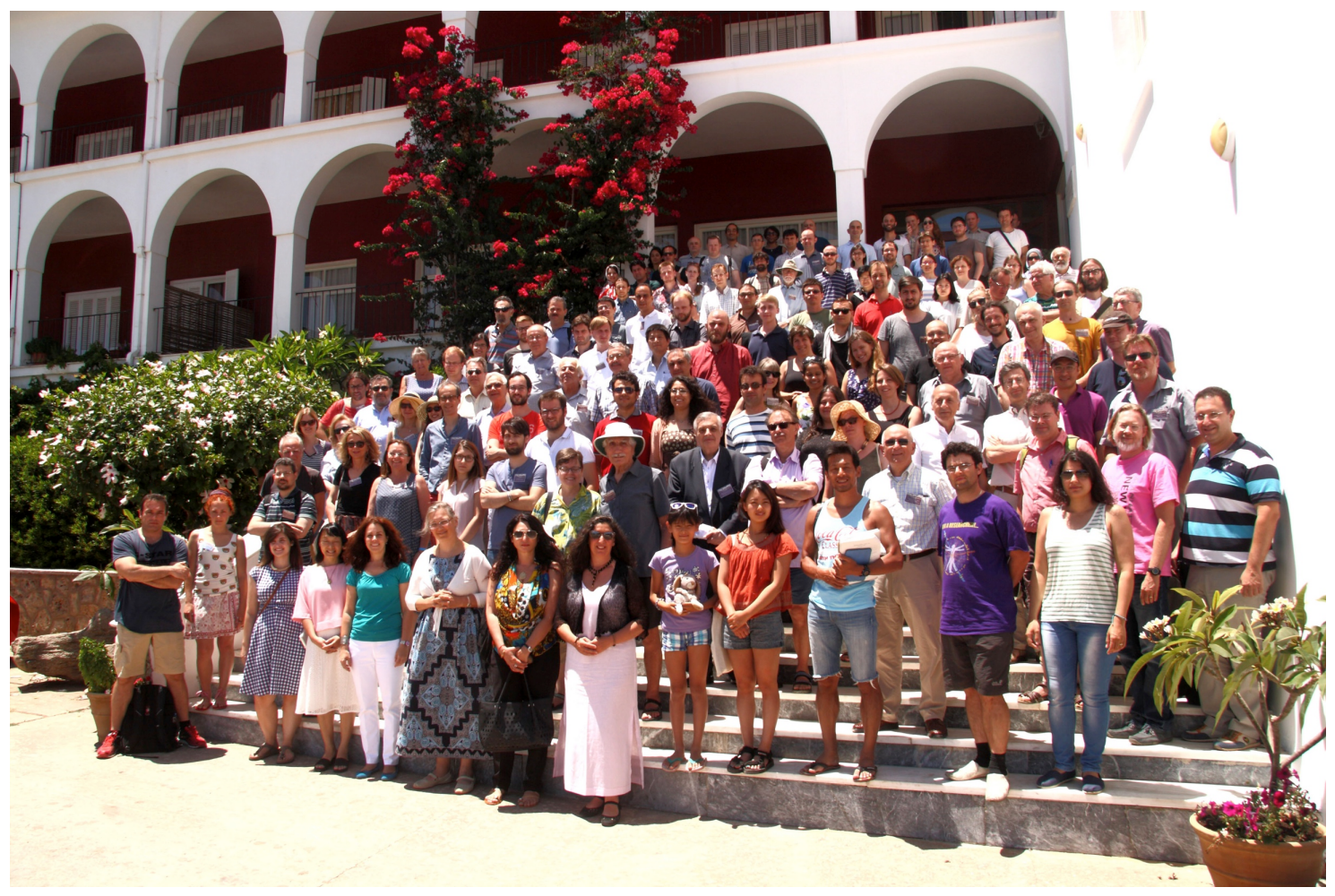

